\title{
Calorie Restriction - An Approach towards Obesity Management
}

\section{Swati Jain* and Som Nath Singh}

Department of Nutrition, Defence Institute of Physiology and Allied Sciences, Lucknow Road, Timarpur, Delhi, India

\begin{abstract}
Obesity is increasing worldwide and has become a public health concern due to associated degenerative diseases and morbidity. Even though overweight and obesity are not life threatening, they qualify themselves as a disease entity. The bulk of literature on obesity says that the external environment largely influences the increase in food intake and is termed scientifically as "obesogenic environment". A "dual approach" that uses both traditional and holistic health can be used to curb this rising trend. Dietary approaches like low calorie diets and increased physical activity are recommended for weight management and prevention of diseases. A number of studies indicate that there is an increased interest in enhancing the use of herbs, bioactive components of foods, traditional diets; owing to their wide spectrum of therapeutic properties for obesity and for the armed forces personnel (under the hypocaloric rations in the field). Therefore, taking the existing scenario of obesity into consideration and the protective role of calorie restriction, this paper provides an insight into the highly convoluted process of dietary restriction and highlights the implications of hypocaloric diets.
\end{abstract}

\section{Keywords: Obesity; Food; Environment; Nutrition; Calorie}

\section{Introduction}

Obesity is now widely accepted as a complex interplay between environmental and genetic factors and is associated with significant morbidity and mortality. Overweight and obesity both independently and in association with other diseases cause and aggravate a large number of health problems. The rise in obesity in the last 20 years has accelerated thinking about the study of food intake stimulated by the external environment. The term "obesogenic environment" has entered into scientific discourse and implies that the influence of the external environment is largely responsible for the increase in food intake [1]. Along with the physical and dietetic focused approaches there are a range of other factors that can impact weight management (Figure 1).

\section{Need to Eat vs. Want to Eat}

In the past, oral urges have been confused with eating behaviours and hunger with appetite. Appetite was often referred to in the same sense as hunger [2]. Earlier, they both were seen as psychic links of the actual mechanisms which control nutrient balance. With clinical observations, the concepts of hunger and appetite can be distinguished from each other now. Later on, Bruce and Kennedy [3] and Anand [4] conceptualized that there are two types of urges to eat, "hunger" located in the hypothalamus and the other "appetite" located in the cerebral cortex where the effect of the hypothalamic factor may be modified by the cortical influence. The two words - Hunger and Appetite, if taken together would rather be an ill-defined phrase. More recently, Egger [5] gave a lucid distinction between the terms and mentioned that appetite is a function of the brain and the psychological desire to eat. It is intertwined with sensory experiences and determined by neuroanatomic associational experiences. Appetite integrates the nutritional realities of the environment such as the sight and smell of food, emotional cues, social situations, and cultural conventions with the internal metabolic demands of hunger. It can go away when distracted and is therefore generally easier to deal with than genuine hunger when trying to reduce one's food intake. Hunger, on the other hand is an instinct. Basically, hunger is the biological need to have to eat. It is a constant, urging drive to seek out food, which doesn't go away with distraction.

The implication is that "liking" may be important for provoking the motivation towards food consumption, but once these are retained it is the upregulation of "wanting" in an obesigenic environment along with insensitivity to homoeostatic signals but over-reactivity to external cues - that promotes over consumption. These changes in the food environment have stimulated food intake beyond what is required to match energy expenditure, and consequently have resulted in weight gain. Hence, need of the hour is to adopt a "dual approach" using both traditional and holistic health practices in order to curb this rising trend in obesity. Low calorie diets have consistently shown to be an effective strategy for losing weight [6], though strict behavioural efforts are needed to maintain the acquired weight loss [7]. In connection, Harvey-Berino [8] highlighted that energy-dense diets rich in fats and refined sugars promote weight gain. Dietary fat restriction alone does not exert effects superior to calorie restriction, thus strengthening the public health message that calories do count.

Calorie Restriction (CR) is a major form of dietary restriction

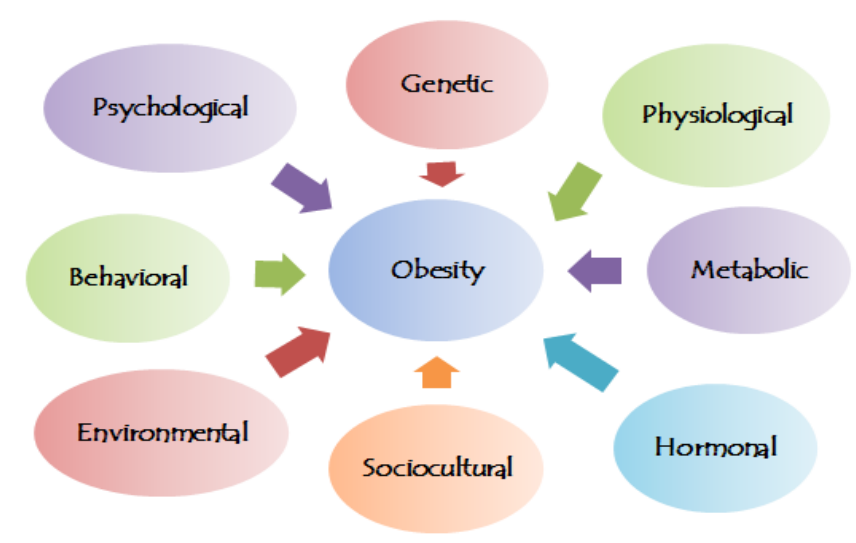

Figure 1: Factors leading to obesity.

*Corresponding author: Dr. Swati Jain, 155, E-space, Nirvana Country, Gurgaon, Haryana- 120018, India, Tel: +91 124-4223960; E-mail: swati.jain.g@gmail.com

Received July 01, 2015; Accepted July 27, 2015; Published August 01, 2015

Citation: Jain S, Singh SN (2015) Calorie Restriction - An Approach towards Obesity Management. J Nutr Disorders Ther S1: 006. doi:10.4172/2161-0509.S1006

Copyright: (C) 2015 Jain S, et al. This is an open-access article distributed under the terms of the Creative Commons Attribution License, which permits unrestricted use, distribution, and reproduction in any medium, provided the original author and source are credited. 
which consists of decreasing daily energy intake by $15-40 \%$ of baseline needs. Although, the intake of calories is reduced, sufficient intake of vitamins, minerals and other essential nutrients must be maintained. The amount of food that can be consumed has two extremes: i) low enough to cause death from starvation, and ii) high enough to lead to obesity, CR lies between these two extremes (Figure 2). CR is the only non-pharmacological intervention known to date, with the potential to extend longevity and improve health parameters and indicators of diseases [9].

Research on CR began much earlier than the twenty first century. A considerable amount of research in the first decade of twenty first century has been an extension to the explorations done in the nineteenth century itself. Restricting energy intake has been explored since 1914, when Francis Peyton Rous reported how reducing food intake inhibited the occurrence of cancers in rodents [10]. A few years later, Osborne and Mendel [11], demonstrated that decreasing food intake led to increased life span of rats. This relationship got stronger scientific basis when McCay et al. [12] reported that retarding the growth of rats by reduction of calorie intake extended their life. This research group pioneered the classic calorie restriction studies on the laboratory rat, which showed that long term $40 \%$ CR without malnutrition reduces body weight and prolongs the life span. In animal experiments, CR is measured as a percentage of food given to an experimental group compared to the amount of food eaten by its own basal food intake or the control group that eats either without restriction or ad libitum e.g., $30 \%$ less, etc. So, the first observations were on rodents which were later on observed across wide range of species like yeast, worms and fish [13]. Data from long term prospective trials on humans are lacking, however, there is a lot to infer from a handful of epidemiological and cross-sectional observations in longer-lived humans and individuals who self-impose CR.

History has many examples where during military missions and for local population, food availability was restricted. Both, armies and general population faced starvation on scarcity of food since maintenance of normal food supply was difficult. The World War II reduced the food intake of many people living in Europe which resulted in anti-aging benefits and fewer cases of hypertension, heart disease and diabetes were reported [14]. Surveillance data from Norwegian population exposed to energy restriction during World War II showed reduced breast cancer risk later in life in association with acute $(<1$ year) energy restriction (about $50 \%$ CR without major changes in diet quality) [15]. Similarly, in 1940s Scandinavians who were surviving on a semi-starvation diet equivalent to about $20 \%$ CR were found to have a reduced incidence of cardiovascular disease [16]. In the fifteenth century, an Italian nobleman Luigi Cornaro reasoned and related his improvement in health to dietary restriction and eventually lived to be a centenarian.

\section{Classical Views and Various Hypotheses on How CR Works}

Even though there has been research on CR for over 70 years, the

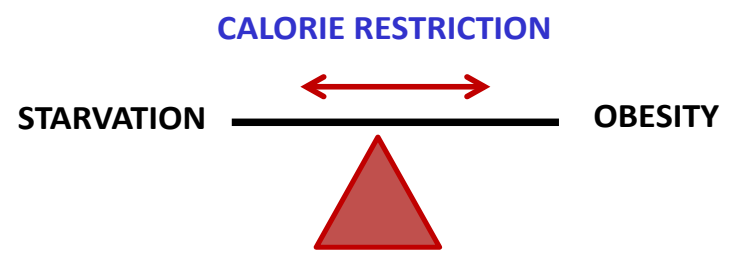

Figure 2: Calorie restriction: an intermediate to starvation and obesity. mechanism by which CR works is still not fully understood. Some of the explanations include reduced cellular divisions, lower metabolic rates, reduced production of free radicals and hormesis. The most widespread theory points to a significant protection from DNA damage due to a reduction of metabolism [17]. Various hypotheses have been proposed to explain the effect of dietary restriction on life span, predominantly in short-lived rodent species, but the role of oxidative stress has attracted the greatest research attention [18]. Recent findings have identified a few molecular pathways that appear to regulate the aging process. Libert and Guarente [19] beheld the view that understanding the molecular mechanisms of CR may lead to the development of novel therapies to combat diseases of aging and thereby improve the quality of life.

\section{Body fat hypothesis}

Berg and Simms [20] came up with their hypothesis somewhat 25 years after McCay et al. gave the retardation of growth hypothesis. Their theory came as a challenge wherein they proposed that CR causes life extension by reducing body fat content; based on the growing obesity rates and therefore it was quite reasonable to think that $\mathrm{CR}$ would decrease the body fat content. This view was however, mainly supported by nutritionists only. Subsequently, in early 1980's this hypothesis was discredited for many years. A study by Redman and Ravussin [21], demonstrated that a 6 month CR intervention induced a decline in body weight but no alteration in abdominal fat was observed. In support of this contention, a new perspective of fat hypothesis lies with the ability of CR to improve insulin action primarily by reducing visceral fat [22].

\section{Pituitary function and CR}

Everitt [23] proposed that pituitary function and CR are linked. He viewed that while pituitary has a role in the regulation of food intake, it is also responsible to cause CR induced decrease in the secretion of an aging factor. The latter view was widely taken up and is still a portent of the current debate on a possible role of the Growth Hormone-IGF-1 axis in the life-extending action of CR. CR induces lower levels of pituitary growth hormone in animals [17]. However, Kenny et al. [24], are the first ones to investigate the effects of chronic mild CR on HPA axis response, and found a slight beneficial effect on stress response. In the midst of the studies, reporting positive findings, there is a dearth of parallel studies reporting the effects of CR on HPA axis.

\section{Metabolic rate hypothesis}

Another hypothesis that gained favour over the leading McCay's retardation of growth hypothesis was proposed by George Sacher in 1977. He presented that CR retards aging by reducing the metabolic rate per unit of body mass [25]. Although Sacher had not measured the metabolic rate, this hypothesis was promoted. There are conflicting views surrounding this; McCarter et al. [26] stated that if CR were to slow metabolism, the production of ROS would decrease consequently, which is not the case as observed in various studies. This placed the beginning to bring up research on how to normalise findings on metabolic rate for differences in body size. Sohal and Forster [27] highlighted in their recent review that the effect of CR on metabolic rate is not brief but long lasting.

\section{Biosphere 2 experiment}

Further on, in the 1990's Walford et al. [28], reported the effect of CR on primate model, Homo Sapiens. Roy Walford, Lisa Walford, and Brian M. Delaney (founders of CR Society International, 1994) developed a nutrient-rich, very low calorie diet known as CRON-diet 
(Calorie Restriction with Optimal Nutrition). The concept of CRONdiet involved the practice of calorie restriction that will improve health and retard aging, along with providing the recommended daily amounts of various nutrients. The CRON-diet was a result of the decades of animal experiments performed by Walford and the Biosphere 2 study [28] and is associated with many physiological, biochemical, and metabolic alterations coherent with CR rodents [21].

\section{Oxidative damage theory}

Currently, this hypothesis is the one approved by most biological gerontologists. In 1990's, Lee and Yu [29] documented that oxidative damage is reduced in CR animals. Later on in 1996, researchers Sohal and Weindruch [30] expanded this view and proclaimed that CR extends life by attenuating oxidative damage.

It is certain that CR delays the age-associated accumulation of cellular oxidative damage. However, it is not yet established that oxidative damage plays a major role in the aging process. One of the possible explanations of this hypothesis could be the increased efficiency in transport of electrons through the respiratory chain. This might reduce the production of ROS and slow aging [31]. A different explanation is that CR poses an increased ability to detoxify ROS which in turn slows oxidative damage. There is lower ROS generation observed in isolated tissue mitochondria from CR rodents, which subsequently leads to lower tissue oxidative stress. However, the data relating CR to detoxification of ROS is inconsistent. For example, the expression of sulphur oxide dismutase enzyme (SOD) increases on lifelong $\mathrm{CR}$, but in genetically altered mice there is no consistent correlation in the expression levels of SOD and life span [32].

\section{Hormesis hypothesis}

The word "hormesis" is derived from the Greek word "hormaein" which means "to excite". The term "hormesis" was coined by Southam and Ehrlich [32] who described this as any beneficial action resulting from the response of an organism to a low-intensity biological stressor. Research has indicated "hormesis" as an explanation for CR. In the year 1998, investigators Turturro et al. [33] independently proposed this hypothesis. This hypothesis provides a basis for studies aimed at understanding the complex nature of the processes that underlie the anti-aging actions of CR. The view mainly gained support during the twenty first century, as it is increasingly apparent that an interaction of multiple processes underlies the life-extending and anti-aging actions of CR.

Based on the concept of Hormesis, Michael Ristow's group in 2007 postulated mitochondrial hypothesis of CR. They proposed that diet imposes a low-intensity biological stress on the organism, which elicits a defensive response and helps to protect it against the causes of aging and improved health. Perhaps the first experimental evidence for hormesis was presented by this group, on a worm Caenorhabditis elegans, which suggested that the restriction of glucose metabolism extends life span mainly by increasing oxidative stress that stimulates the organism into exhibiting an increased resistance to further oxidative stress [34].

\section{Protein turnover}

This theory suggests that reduction in protein turnover and accumulation of oxidatively damaged proteins which are also potentially harmful may cause aging $[35,36]$. Experimental evidences in previous studies led to the conclusion that CR related increase in longevity are associated with enhanced protein turnover [30]. During CR, as there is reduction in fat biosynthesis, the degradation of proteins is triggered, thereby increasing their turnover. The data suggest an increase in protein turnover during $\mathrm{CR}$, but the elevated turnover during $\mathrm{CR}$ is not uniform; although some damaged proteins were degraded, others continued to accumulate [37].

Like all other effects of CR, this is also surrounded with differing results $[38,39]$.

\section{Metabolic Effects of Calorie Restriction}

Metabolic changes occur as a result of a two phase mechanism of $\mathrm{CR}$ in mammals- i) an adaptive period immediately after the regimen is imposed ii) steady state period, which can last till the lifetime of the animal.

Adaptive Phase: An array of changes takes place during the adaptive phase. Glucose metabolism regulates secretion of insulin from the pancreatic $\beta$-cells. As an immediate response to low levels of glucose, the glycogen stores begin to degrade upon the secretion of glucagon from the pancreas. After the carbohydrates have been depleted, lipolysis begins to compensate for the lack of glucose in the blood [40]; also resulting in loss of fat mass in calorie restricted animals [41]. Degradation of fat and protein leads to ketogenesis. Also, liver up-regulates the expression of enzymes involved in gluconeogenesis and down-regulates those in glycolysis [42]. During this phase of CR, metabolism rate as measured by oxygen consumption also declines [43].

Steady State: During this phase, $\beta$-cells sense the low glucose levels, and correspondingly produce less insulin, as the blood glucose levels are still below normal level during the steady state resulting in lowered blood insulin levels $[44,45]$. The organism reaches a steady state in which ketones help meet energy needs of the brain. An increase in the coupling of oxidative phosphorylation to ATP synthesis, by a reduction in levels of uncoupling proteins also takes place leading to a reduction in body temperature [46].

\section{Changes in the Neuroendocrine System}

The endocrine system is extremely integrated where a change in one factor affects the other hormone. Neuroendocrine system has long been thought to play a role in aging and many changes observed in the CR mammals indicate a direct or indirect association with the neuroendocrine system. CR alters expression of hormones significantly, resulting in delayed senescence. There is evidence that anterior pituitary hormones - growth hormone (GH), prolactin, thyroid stimulating hormone (TSH), luteinizing hormone (LH), follicle stimulating hormone (FSH), impinge on life span and age related pathology. All these hormones contribute to complex physiological functions such as growth, reproduction, mitochondrial function and stress resistance, which have an effect on aging processes. Characteristically, CR mammals have lower levels of GH, TSH, IGF-1, and gonadotropins [47]. Conversely, glucocorticoids, catecholamines, and glucagon increase [48]. Han et al. [49] reported that secretion of most hormones is greatly reduced by CR except corticosterone. The most constant response observed on a CR regime across species and strains has been suppressed circulating insulin levels and increased insulin sensitivity [50].

However, the degree and extent of CR induced is a major determinant for the levels of regulatory peptides. Long term, short term and intermittent dietary restriction feeding regimens may produce different effects on the biomarkers. A study from our laboratory showed 
that short term CR (25\%) regime when induced for 5 days demonstrated significant effects on appetite regulatory peptides. Plasma levels of orexigenic peptides like ghrelin and NPY were found to be increased with reduction in CCK, IGF-1 and circulating T3 levels, with no change in the insulin levels. Leptin decline has an appetite stimulating effect which explains the lower than the detectable concentrations of leptin observed on short term dietary restriction in rats [51].

Besides, hypocaloric diets are an implication of combat situations also. The soldiers' ration is hypocaloric in energy content relative to their daily expenditure in short term assault situations. This is a limitation imposed by ration design and mission constraints. Research group led by Shukitt-Hale [52] and the committee of IOM [53], articulated some basic ideas about the soldiers' diet and health during the missions (Box-1). As the state of negative energy balance proceeds performance is compromised and appetite is increased, even under stressed conditions [54]. The nutritional composition of ration would be optimized to best sustain physical and cognitive performance and to prevent possible adverse health consequences. The rations designed for short term use by the warfighters must be adequate for the nutritional needs of the extremely intense and highly mobile combat situations [55].

\section{BOX-1}

\section{Ration Constraints during Assault Mission}

- During combat operations the expected daily energy expenditure is $4000-4500 \mathrm{Kcal}$, through intermittent periods of high energy expenditure mixed with longer periods of low intensity movement.

- Soldiers possibly have an average energy intake of $2400 \mathrm{kcal} / \mathrm{day}$.

- Assault rations take care of only $60 \%$ of the energy needs of the combat soldiers.

- The daily ration must fit in 0.12 cubic feet and weigh 3 pounds or less.

- The soldiers rely on this ration for 3-7 days followed by 1-3 days of recovery when they would have access to more nutritionally complete meals.

- During combat these troops will therefore experience an energy deficit of $1600-2100 \mathrm{kcal} / \mathrm{day}$.

Energy restriction results in a constant feeling of hunger. In concert, Redman and Ravussin [21] in their review indicated the participants on CR regimen, reported an increased desire to eat and a decreased satisfaction of appetite after 6 months. Furthermore, mood and Quality of Life (QOL) indicators are imperative, as a factor to assess the feasibility of CR in humans. While the Minnesota Semi Starvation study [54] indicated that CR can negatively affect mood, the results of the CALERIE and MAEDS trials depict no negative effect on mood; instead found a decline in the symptoms of depressed mood in the CR group. Experimental evidence suggests that that increased appetite has been known to interfere with the ability to perform maximally [55]. Researchers- Gibson and Green [56] reported that it is the psychological preoccupation of food and feelings of hunger that are associated with afflicted performance than by a physiologic effect of low energy intake. Training soldiers to ignore the hunger feelings may be a very challenging task. However, reducing the appetite by hypohydration or stress to the extent that the thoughts of food even are eliminated is not beneficial [57]. A study by Laessle et al. [58] presented that during the low calorie periods the subjects reported stronger hunger pangs, thought more about food and exhibited difficulties concentrating, had greater fatigue than during the ad libitum periods even on minimal weight loss. Therefore, altering the appetite by causing its reduction might be beneficial in elevating mood and cognitive performance. Indeed, Fischer et al. [59] has reported declining hunger sensations to be associated with being more energetic. However, disagreement revolves around the effect on cognitive performance under CR in humans.

To reduce the negative psychological and physiological impact of restricted eating like hunger pangs, a satiety based approach / use of pharmacologic appetite suppressants may be considered [60]. Drugsthe pharmacological agents control or reduce weight by altering the fundamental processes of the human body, like altering appetite, metabolism or absorption of calories [61]. Also, appetite suppressants have found their way already, in suppressing appetite for those under the hypocaloric rations in the field. As reviewed above, the physiological and mental status of the soldiers determine the success of a military operation and maximize performance and effectiveness. Use of appetite suppressants dates back to the First World War, when the drug- MDMA was experimented as an interrogation tool in Project MKUltra by the US Army [62]. British military used 72 million amphetamine tablets in the Second World War. At that time, diets of the soldiers were supplemented with the compound amphetamine, in order to reduce the hunger and to increase their fighting capacity [63].

Soldiers also consume other bio-actives (L-carnitine, creatine) and substances that are already consumed at liberty in either the sports community or the general population (e.g., Ginkgo biloba and Ginseng extracts) with the goal of increasing physical endurance. In recent years, there has been an increased interest among sports community in enhancing the use of herbs, bioactive components of foods and traditional diets to optimize physical and mental performance. These include a variety of substances ranging from essential and nonessential amino acids, metabolites, energy enhancers, muscle builders and stimulants such as caffeine. Recent research has shown that Hoodia gordonii, herb of African origin works as an appetite suppressant under short term calorie restriction [64]. Taking into consideration, the extent of physical burden the soldiers go through during operations, developing operation- suitable ration is of importance to enhance soldier's performance. During sustained operations (SUSOPS), combat foot soldiers carry loads in excess of $50 \mathrm{~kg}$ for 3-7 days under weather conditions that vary from cold, mountainous to humid, tropical climates. In view of the fact, that the physiological and nutritional status of soldiers can markedly affect the success of military operations discernibly, frontline soldiers might gain a performance edge with the use of non-traditional food components, stimulants, and herbals that might act as ergogenic aids $[53,65]$.

\section{Conclusion}

Given that exercise and diet remain the interminable basis for weight control, their use should be collective i.e. with regular exercise as well as dietary and behavioural modifications weight loss can be achieved. Research has shown that use of multiple phytochemicals might result in a synergistic and enhanced effect. Nonetheless, there is lack of evidence to demonstrate that the phytochemicals used as appetite suppressants and anti- obesity agents are effective and safe. Regardless of this, several natural appetite suppressants are available as non-prescription herbal preparations. Even though some plants have shown promising results in the short term, there is still a need for more human clinical trials and longer duration studies to substantiate the traditional claims for these plant extracts. Most importantly, whether the effect is achieved at an appropriate and safe dose remains a matter of investigation. In light of the existing controversy, further research 
is needed to determine the actual picture of feasibility and safety of $\mathrm{CR}$ in humans for adherence to hypocaloric diets. Nonetheless, this review highlights the importance of calorie restriction in conditions like obesity and combat operations.

\section{References}

1. Mackenbach JD, Rutter H, Compernolle S, Glonti K, Oppert JM, et al. (2014) Obesogenic environments: a systematic review of the association between the physical environment and adult weight status, the SPOTLIGHT project. BMC Public Health 14: 233.

2. Hamburger WW (1957) Psychological aspects of obesity. The bulletin of the New York Academy of Medicine 33: 771-782

3. Bruce HM, Kennedy JC (1951) The central nervous control of food and water intake. Proceedings of the Royal Society of London 138: 528-544.

4. Anand BK (1960) Nervous regulation of food intake. American Journal of Clinical Nutrition 8: 529-534.

5. Egger G (2012) Hunger versus appetite. Medical observer.

6. Davoodi SH, Ajami M, Ayatollahi SA, Dowlatshahi K, Javedan G, et al. (2014) Calorie shifting diet versus calorie restriction diet: a comparative clinical trial study. International Journal of Preventive Medicine 5: 447-456.

7. Bond DS, Phelan S, Leahey TM, Hill JO, Wing RR (2009) Weight-loss maintenance in successful weight losers: surgical vs non-surgical methods. International Journal of Obesity (London) 33: 173-180.

8. Harvey-Berino $\mathrm{J}$ (1999) Calorie restriction is more effective for obesity treatmen than dietary fat restriction. Annals of Behavioural Medicine 21: 35-39

9. Bray GA (2008) Lifestyle and pharmacological approaches to weight loss: efficacy and safety. Journal of Clinical Endocrinology and Metabolism 93: 81-88.

10. Rous $P$ (1914) The influence of diet on transplanted and spontaneous tumors. Journal of Experimental Medicine 20: 433-451.

11. Osborne TB, Mendel LB, Ferry ER (1917) The effect of retardation of growth upon the breeding period and duration of life in rats. Science 45: 294-295.

12. McCay CM, Maynard LA, Sperling G, Barnes L (1939) Retarded growth, life span, ultimate body size, and age changes in the albino rat after feeding diets restricted in calories. Journal of Nutrition 18: 1-13.

13. Heilbronn LK, Ravussin E (2003) Calorie restriction and aging: review of the literature and implications for studies in humans. American Journal Clinical Nutrition 78: 361-369

14. Van Itallie TB, Hirsch $L$ (1979) Appraisal of excess calories as a factor in the causation of disease. American Journal of Clinical Nutrition 32: 2648-2653.

15. Tretli S, Gaard M (1996) Lifestyle changes during adolescence and risk of breast cancer: an ecologic study of the effect of World War II in Norway. Cancer causes and control 7: 507-512.

16. Strom A, Jensen RA (1951) Mortality from cardiovascular disease in Norway 1940-1945. Lancet 1: 126-129.

17. Koubova J, Guarente L (2003) How does calorie restriction work? Genes and Development 17: 313-321.

18. Sanz A, Pamplona R, Barja D (2006) Is the mitochondrial free radical theory of aging intact? Antioxidants and Redox Signalling 8: 582-599.

19. Libert S, Guarente L (2013) Metabolic and neuropsychiatric effects of calorie restriction and sirtuins. Annual Review of Physiology 75: 669-684.

20. Berg BN, Simms HS (1960) Nutrition and longevity in the rat. II. Longevity and onset of disease with different levels of food intake. Journal of Nutrition 71: 255-263.

21. Redman LM, Ravussin E (2011) Caloric restriction in humans: impact on physiological, psychological, and behavioral outcomes. Antioxidants \& Redox Signaling 14: 275-287.

22. Mobbs CV, Yenk, Hof PK (2007) Mechanism of Dietary Restriction in Aging and Disease. Interdisciplinary topics in gerontology. Basel. Karger 35: 1-17.

23. Everitt AV (1973) The hypothalamic-pituitary control of aging and age-related pathology. Experimental Gerontology 8: 265-277.

24. Kenny R, Dinan T, Cai G, Spencer SJ (2014) Effects of mild calorie restriction on anxiety and hypothalamic-pituitary-adrenal axis responses to stress in the male rat. Physiological Reports 2: e00265.

25. Sacher GA (1977) Life table modifications and life prolongation. Handbook of the Biology of Aging, New York: Van Nostrand Reinhold 582-638.

26. McCarter R, Masoro EJ, Yu BP (1985) Does food restriction retard aging by reducing the metabolic rate? American Journal of Physiology 248: E488-E490.

27. Sohal RS, Forster MJ (2014) Caloric restriction and the aging process: a critique. Free Radical Biology \& Medicine.73: 366-382

28. Walford RL, Harris SB, Gunion MW (1992) The calorically restricted lowfat nutrient rich diet in Biosphere-2 significantly lowers blood glucose, total leukocyte count, cholesterol, and blood pressure in humans. Proceedings of the National Academy of Sciences USA 89: 11533-11537.

29. Lee DW, Yu PY (1991) The age-related alterations in liver microsoma membranes: the effects of lipid peroxidation and dietary restriction. Liver and Aging, Amsterdam: Excerpta Medica 17-26.

30. Sohal RS, Weindruch R (1996) Oxidative stress, caloric restriction and aging Science, 273: 50-63

31. Weindruch R, Walford RL, Fligiel S, Guthrie D (1986) The retardation of aging in mice by dietary restriction: longevity, cancer, immunity and lifetime energy intake. Journal of Nutrition 116: 641-654.

32. Hauck SJ, Bartke A (2000) Effects of growth hormone on hypothalamic catalase and $\mathrm{Cu} / \mathrm{Zn}$ superoxide dismutase. Free Radical Biology and Medicine 28: $970-978$.

33. Southam CM, Ehrlich J (1943) Effects of extracts of western red-cedar heartwood on certain wood-decaying fungi in culture. Phytopathology 33: 517524.

34. Turturro A, Hass B, Hart RW (1998) Hormesis - implications for risk assessment caloric intake (body weight) as an exemplar. Human and Experimental Toxicology 17: 454-459.

35. Schulz TJ, Zarse K, Voigt A, Urban N, Birringer M, et al. (2007) Glucose restriction extends Caenorhabditis elegans life span by inducing mitochondrial respiration and increasing oxidative stress. Cell Metabolism 6: 280-293.

36. Lavie L, Reznick AZ, Gershon D (1982) Decreased protein and puromycinylpeptide degradation in livers of senescent mice. Biochemical Journal 202: 47 51.

37. Gracy RW, Chapman ML, Cini JK, Jahani M, Tollefsbol TO, et al. (1985) Molecular basis of the accumulation of abnormal proteins in Progeria and aging fibroblasts. Basic Life Sciences 35: 427-442.

38. Lee CK, Klopp RG, Weindruch R, Prolla TA (1999) Gene expression profile of aging and its retardation by caloric restriction. Science 285: 1390-1393.

39. Price JC, Khambatta CF, Li KW, Bruss MD, Shankaran M, et al. (2012) The effect of long term calorie restriction on in vivo hepatic proteostatis: a nove combination of dynamic and quantitative proteomics. Molecular \& Cellular Proteomics 11: 1801-1814.

40. Miller BF, Robinson MM, Reuland DJ, Drake JC, Peelor FF, et al. (2012) Calorie restriction does not increase short-term or long-term protein synthesis. J Gerontol A Biol Sci Med Sci 68: 530-538.

41. Scrofano MM, Shang F, Nowell Jr TR, Gong X, Smith DE, et al. (1998) Aging calorie restriction and ubiquitin-dependent proteolysis in the livers of Emory mice. Mechanisms of Ageing and Development 101: 277-296.

42. Bertrand HA, Lynd FT, Masoro EJ, Yu BP (1980) Changes in adipose mass and cellularity through the adult life of rats fed ad libitum or a life-prolonging restricted diet. Journal of Gerontology 35: 827-835.

43. Barzilai N, Gabriely I (2001) The role of fat depletion in the biological benefits of caloric restriction. Journal of Nutrition 131: 903S-906S.

44. Dhahbi JM, Mote PL, Wingo J, Rowley BC, Cao SX, et al. (2001) Caloric restriction alters the feeding response of key metabolic enzyme genes. Mechanisms of Ageing and Development 122: 1033-1048.

45. McCarter RJ, McGee JR (1989) Transient reduction of metabolic rate by food restriction. American Journal of Physiology 257: E175-E179.

46. Greene AE, Todorova MT, McGowan R, Seyfried TN (2001) Caloric restriction inhibits seizure susceptibility in epileptic EL mice by reducing blood glucose. Epilepsia 42: 1371-1378

47. Lane MA, Baer DJ, Rumpler WV, Weindruch R, Ingram DK, et al. (1996) 
Calorie restriction lowers body temperature in rhesus monkeys, consistent with a postulated anti-aging mechanism in rodents. Proceedings of the National Academy of Sciences 93: 4159-4164.

48. Mobbs CV, Bray GA, Atkinson RL, Bartke A, Finch CE, et al. (2001) Neuroendocrine and pharmacological manipulations to assess how caloric restriction increases lifespan. Journal of Gerontology Series A, Biological Sciences and Medical Sciences 56: B34-B44.

49. Klebanov S, Diais S, Stavinoha WB, Suh Y, Nelson JF (1995) Hyperadrenocorticism, attenuated inflammation, and the life-prolonging action of food restriction in mice. Journal of Gerontology Series A, Biological Sciences and Medical Sciences 50: B79-B82.

50. Han ES, Evans TR, Shu JH, Lee S, Nelson JF (2001) Food restriction enhances endogenous and corticotropin-induced plasma elevations of free but not total corticosterone throughout life in rats. Journal of Gerontology Series A Biological Sciences and Medical Sciences 56: B391-B397.

51. Roth GS, Lane M, Ingram DK, Mattison J, Elahi D, et al. (2002) Biomarkers of caloric restriction may predict longevity in humans. Science 297: 811.

52. Jain S, Singh SN (2013) Short term calorie restriction: effects on endocrine markers of nutritional status. Endocrine Abstracts 31: P227.

53. Shukitt-Hale B, Askew EW, Lieberman HR (1997) Effects of 30 days of undernutrition on reaction time, moods, and symptoms. Physiology and Behaviour 62: 783-789.

54. Committee on Optimization of Nutrient Composition of Military Rations for Short-term, High-stress Situations, Committee on Military Nutrition Research (2005) Nutrient Composition of Rations for Short-Term, High-Intensity Combat Operations. Institute of Medicine Washington, DC: The National Academy Press.

55. Keys A, Brozek J, Henschel A, Mickelsen O, Taylor HL (1950) The biology of human starvation (I-II), Minneapolis: University of Minnesota Press.
56. Stubbs J, Ferres S, Horgan G (2000) Energy density of foods: Effects on energy intake. Critical Reviews in Food Science and Nutrition 40: 481-515

57. Gibson LE, Green MW (2002) Nutritional influences on cognitive function: Mechanisms of susceptibility. Nutrition Research Reviews 15: 169-206.

58. Committee on Military Nutrition Research, Institute of Medicine (1995) No Eating Enough. Institute of Medicine The National Academy Press, Washington DC

59. Laessle RG, Platte P, Schweiger U, Pirke KM (1996) Biological and psychological correlates of intermittent dieting behavior in young women. A model for bulimia nervosa. Physiology and Behaviour 60: 1-5.

60. Fischer K, Colombani PC, Wenk C (2004) Metabolic and cognitive coefficients in the development of hunger sensations after pure macronutrient ingestion in the morning. Appetite 42: 49-61.

61. Halford JC, Harrold JA (2012) Satiety-enhancing products for appetite control: science and regulation of functional foods for weight management. Proceedings of Nutrition Society $71:$ 350-362.

62. Chandrasekaran CV, Vijayalakshmi MA, Prakash K, Bansal VS, Meenakshi J et al. (2012) Herbal Approach for Obesity Management. American Journal of Plant Sciences 3: 1003-1014.

63. Lowlinson JH, Ruiz P, Millman RB, Langrod JG (1997) Substance Abuse: A Comprehensive Textbook (3rdedn), Baltimore : Williams and Wilkins.

64. Tyler A (1986) Street Drugs. Great Britain: Hodder \& Stoughton.

65. Jain S, Singh SN (2014) Metabolic response of short term calorie restriction and supplementation with Hoodia gordonii. South African Journal of Botany 92: 73-77.
This article was originally published in a special issue, Nutritional Disorders handled by Editor(s). Dr. Anjana Agarwal, SNDT Women University, Mumbai 